\title{
O PENSAR E A FIGURA SOCRÁTICA COMO ECOS DE SUPERAÇÃO DA CRISE NA EDUCAÇÃO NA PERSPECTIVA DE HANNAH ARENDT
}

\author{
Raphaela Cândido* \\ Lara França da Rocha**
}

\begin{abstract}
RESUMO: Este texto discorre sobre a compreensão da crise na educação, inserida num contexto de esfacelamento da política mundial. A busca desse entendimento se dá a partir da abordagem de Hannah Arendt, posto que ela traz a figura de Sócrates como aquele que priorizou a atividade do pensamento como prática e ensino, condição de possibilidade para a superação dos colapsos provocados pelas fronteiras nas quais a educação tem sido demarcada.
\end{abstract}

Palavras-chave: educação; pensamento; crise; superação.

RESUMEN: Este artículo trata sobre la comprensión de la crisis en la educación, frente a un contexto de desintegración de la política mundial. La consecución de este entendimiento se lleva a cabo desde la perspectiva de Hannah Arendt, puesto que ella trae la figura de Sócrates como aquel que prioriza la actividad del pensamiento en cuanto práctica y enseñanza, como condición de posibilidad para superar los colapsos causados por las fronteras dentro de las cuales la educación ha sido demarcada.

Palabras clave: educación; pensamiento; crisis; superación.

\section{A Crise na educação é também uma crise política}

O desafio político proposto por nosso tempo fala diretamente à educação. Se os modos de convivência humana e as diversas instâncias fundadas não mais garantem aos indivíduos a segurança necessária para a apreensão lógica e coerente do mundo, instaura-se uma crise no âmago do modus operandi do homem se relacionar com ele

\footnotetext{
* Doutoranda em Filosofia pela Universidade Federal do Ceará e em Psicologia Social pela Universidad John Kennedy, em Buenos Aires. Mestra em Filosofia pela Universidade Estadual do Ceará e Especialista no Ensino de História. Professora da Faculdade Católica de Fortaleza e da Rede Estadual de Ensino do Ceará. E-mail: mandarinrb@yahoo.com.br.

${ }^{* *}$ Mestranda em Filosofia pela Universidade Federal do Ceará. E-mail: larafr87@gmail.com.
}

mesmo e com a realidade dada em primeira instância.

Inserida no centro desses debates e desse cenário de conflito, a educação tornou-se um ponto nevrálgico nessa conjuntura tensa que se concretizou mormente no delineamento da coisa pública. Já que o ensino foi utilizado na maior parte da história, enquanto importante canal de sustentação do status quo vigente, o imperativo contemporâneo se desvela num outro vértice específico dessa área de desenvolvimento humano. Como aguçar nos recém-chegados o interesse e a responsabilidade não apenas pelos conteúdos científicos, mas pelo mundo que herdaram dos antepassados? Mesmo num cenário global caótico, como despertar nos novos o sentimento de pertença e de íntima relação destes com o espaço em que

CÂNDIDO, Raphaela; ROCHA, Lara França da. O pensar e a figura socrática como ecos de superação da crise na educação na perspectiva de Hannah Arendt. Revista Sul-Americana de Filosofia e Educação. Número 30: nov./2018-abr.2019, p. 20-37. DOI: https://doi.org/10.26512/resafe.vizo.28237 
vivem? Como a pessoa pode ser educada para esta compreensão?

A busca para responder a tais questões pode partir das pistas deixadas por Hannah Arendt em seus escritos sobre a relação entre educação e política, com uma particular compreensão do que seria educar e de qual o seu papel. A teórica política enfatiza que esta deve ser pensada para além da instrução para habilidades, precisando, nessa conjuntura, ser abordada partindo de dois ângulos diferentes:

Em primeiro lugar, ela considerou a educação das crianças e, nessas passagens, sempre enfatizou que a condição humana que está crucialmente envolvida é a natalidade, $o$ fato de que as crianças nascem como 'novos começos', nascidos para rejuvenescer e renovar a mundo Sua educação deve fomentá-los nesta função essencial. Ela insistiu, então, que as crianças deveriam ser educadas conservadoramente, no sentido de que elas são introduzidas no passado que é conservado para elas, como sua herança; [...] A educação de adultos é completamente diferente. A condição humana crucialmente envolvida nele é 'estar no mundo'. Os adultos se educam um ao outro para estar no mundo, o que, em circunstâncias históricas variadas, pode significar sentir-se em casa no mundo, ou ser alienado dele, ou alguma mistura desses modos. No mundo moderno, os adultos não se entregam, conservadoramente, uma tradição compartilhada, têm que fazer um mundo comum. (YOUNG-BRUEHL in GORDON, 2001, p.226-227.)
Para responder às questões e aos imperativos hodiernos, Arendt apreende que o esfacelamento da tradição, gerada pela profunda crise contemporânea, não se reduz apenas a alguma determinada área de desenvolvimento humano (2003). Se as inquietações e as perplexidades a nível político refletem-se diretamente também no campo acadêmico e intelectual, deparamo-nos com a análise imperativa acerca do homem e de seus desdobramentos, principalmente se nosso enfoque é a educação. De fato, é inegável que o chão firme da tradição não é mais capaz de responder com exatidão às novas problemáticas vivenciadas na contemporaneidade.

Em consonância com nosso escólio de que a autora percebe o esfacelamento da tradição e a incapacidade desta em responder com clareza e nitidez às questões mais atuais, Lafer assim nos elucida:

Os padrões morais e as categorias políticas que compunham a continuidade histórica da tradição ocidental se tornaram inadequados não só para fornecer regras para a ação - problema clássico colocado por Platão - ou para entenderem a realidade histórica e os acontecimentos que criaram o mundo moderno - que foi a proposta hegeliana - mas, também, para inserirem as perguntas relevantes no quadro de referência da perplexidade contemporânea. Em outras palavras, o esfacelamento da tradição implicou na perda de sabedoria, isto é, para falar com Karl W. Deustsch, na dificuldade de discernir, num contexto, as classes 
de perguntas que devem ser feitas. (LAFER in ARENDT, 2003, p. 10-11).

Essa ruptura deve-se ao ineditismo do fenômeno totalitário, cuja novidade reside no fato inconteste de que seus desdobramentos não se restringem à esfera pública, mas invadem também a vida privada e individual, não deixando espaço para a ação e muito menos para a reflexão (ARENDT, 2004, p. 526-527). Privados de nossa instrumentalidade habitual de compreensão, deparamo-nos com a cristalização desse evento, enquanto a concretização da corrosão do clássico e a consolidação da crise hodierna. "A originalidade do totalitarismo é atroz [...] porque suas ações constituem uma ruptura [...]; elas demoliram nossas categorias de pensamento político e nossos critérios de julgamento moral" (ARENDT, 2011, p. 332).

Esse cenário de crise obviamente não se restringe a uma determinada localidade, o que faz com que essa ruptura se apresente de diversas formas. Arendt, porém, destaca a crise no sistema educacional americano e defende que há uma profunda relação entre o colapso deste com a convulsão política e mundial, que ganhou contornos desastrosos desde o fim da I Guerra Mundial. A autora ainda afirma que os esforços das autoridades educacionais não obtiveram o sucesso necessário em uma possível reforma da educação porque trataram essa problemática como um fato isolado ou com menos importância do que a observação e a análise das manobras políticas contemporâneas.
Certamente, há aqui mais que a enigmática questão de saber porque Joãozinho não sabe ler. Além disso, há sempre a tentação de crer que estamos tratando de problemas específicos confinados a fronteiras históricas e nacionais, importante somente para os imediatamente afetados. É justamente essa crença que se tem demonstrado invariavelmente falsa em nossa época: pode-se admitir como uma regra geral neste século que qualquer coisa que seja possível em um país pode, em futuro previsível, ser igualmente possível em praticamente qualquer outro país (ARENDT, 2003, p. 222).

A crise da educação é generalizada, posto que ultrapassa as barreiras nacionais e as peculiaridades regionais. Todavia, ela se configura em um problema universal, e o exame sobre ela é um imperativo hodierno. Os acontecimentos mundiais e as catástrofes da primeira metade do século XX impuseram outra missão à educação: contribuir para a análise dos fenômenos e cooperar para que eles não se repitam (ADORNO, 2012).

É inegável que a educação e a política caminharam em consonância durante praticamente toda a história. "O papel desempenhado pela educação em todas as utopias políticas, a partir dos tempos antigos, mostra o quanto parece natural iniciar um novo mundo com aqueles que são por nascimento e por natureza novos" (ARENDT, 2003, p. 225). Entretanto, há também um grave equívoco nessa contextura, já que há o risco iminente de que a educação se reduza a me- 
ra doutrinação das ideologias dominantes, intervenção pressuposta mais na superioridade do adulto do que até mesmo na preleção de conhecimento ou no senso de responsabilidade e de ética, e isso certamente "só pode significar o desejo de arrancar das mãos dos recém-chegados sua própria oportunidade face ao novo" (ARENDT, 2003, p. 226).

Tomando como base as observações da teórica sob o sistema educacional americano, é mister concebermos a relevância do papel político da educação num país com alto fluxo de imigrantes. Nessa conjuntura, é fácil difundir a ideia de que a construção de um mundo 3 novo ocorre concomitantemente ao ensino dos novos indivíduos. Porém, "é claro que a verdadeira situação não é esta. $\mathrm{O}$ mundo no qual são introduzidas as crianças [...] é um mundo preexistente" (ARENDT, 2003, p. 226). Obviamente, tal assertiva não nega a possibilidade de modificação do status quo, ao contrário, nos brinda com as bases da teoria arendtiana. Para ela, a crise da educação, enquanto reflexo de uma ruptura política muito mais ampla, refere-se ao fato de que os recémchegados, através desta área do desenvol-

\footnotetext{
3 Para a compreensão ideal sob a temática abordada, é fundamental considerarmos como Arendt entende e interpreta o conceito de mundo. Segundo a autora, tal conceito é o espaço que possibilita o surgimento da política, da esfera pública e da convivência entre os homens. Segundo Mascaro, Oliveira e Silva, podemos aferir que: "Para Hannah Arendt, o mundo seria o interespaço onde ocorrem as relações humanas ao mesmo tempo em que o resultado de seu agir e fazer, inclusive nos âmbitos intelectual ou espiritual, desde que objetivados enquanto mundo real”. MASCARO, Laura Degaspore Monte; OLIVEIRA, Luciana Garcia; SILVA, Thiago Dias. Nota dos Tradutores. In: ARENDT, Hannah. Escritos Judaicos. Barueri: Amarilys, 2016. p. 11.
}

vimento humano, não são convidados a conhecer o mundo preexistente do qual fazem parte e, com isso, preparados também para a possibilidade da fundação, inerente à cada indivíduo.

É mister salientar também que, tomando como base a perspectiva arendtiana, a ideia de igualdade inserida no contexto do sistema educacional tem uma conotação dúbia. Ao passo que se fundamenta nas legislações pós-Revolução Francesa, e referese a um ideal de equidade de oportunidades, esta não deve se refletir em sala de aula como um nivelamento das distinções, ou ainda, na tentativa de uniformizar os alunos, extinguindo maximamente possível as suas diferenças. Por mais que, didaticamente, seja necessário levar em consideração o grupo, é importante também não esquecer que as singulares não podem ser suprimidas. Afinal, é o fato de que somos diferentes e completamente únicos em relação a todos aqueles que já vieram ao mundo, como também aos que ainda virão, que possibilita não apenas o próprio baldrame da política, como também de todas as outras atividades humanas. Essa diferença refere-se, na teoria arendtiana, à condição humana da pluralidade. "A pluralidade é a condição da ação humana pelo fato de sermos todos os mesmos, isto é, humanos, sem que ninguém seja exatamente igual a qualquer pessoa que tenha existido, exista ou venha a existir" (ARENDT, 2009, p. 16).

Destarte, a educação é conditio per quam de toda e qualquer sociedade. Porém, é de sua natureza a dinâmica constante inerente ao próprio processo educativo, já que ela constantemente se renova pela natalidade, ou seja, pelo advento de novos seres 
humanos. Esse movimento permanente pressupõe, todavia, muito além do repasse de informações científicas.

Segundo a teórica por nós abordada:

A educação está entre as atividades mais elementares e necessárias da sociedade humana, que jamais permanece tal qual é, porém se renova continuamente através do nascimento, da vinda de novos seres humanos. Esses recém-chegados, além disso, não se acham acabados, mas em um estado de vir a ser. Assim, a criança, o objeto da educação, possui para o educador um duplo aspecto: é nova em um mundo que lhe é estranho e se encontra em processo de formação; é um novo ser humano e um ser humano em formação. (ARENDT, 2003, p. 234-235).

A educação diz respeito, em sua essência, tanto ao fato de que a criança é um ser em formação, o que presume naturalmente uma responsabilidade intrínseca pela sua vida e pelo seu desenvolvimento, quanto ao fato de que as novas gerações precisam também ser preparadas para assumir a responsabilidade pela continuidade do mundo. Arendt nos indica, nesta direção, que "a criança requer cuidado e proteção especiais para que nada de destrutivo lhe aconteça por parte do mundo. Porém também o mundo necessita de proteção para que não seja derrubado e destruído pelo assédio do novo que irrompe sobre ele a cada nova geração" (2003, p. 235).

Nessa conjuntura de dupla responsabilidade, em relação ao desenvolvimento da criança e na garantia da preservação do espaço humano, a escola se revela como sendo o primeiro contato do recém-chegado com o mundo, porém, sem ela mesma se constituir em sua totalidade enquanto tal. Desse modo, podemos indicar que ela se estabelece essencialmente como a "instituição que interpomos entre o domínio do privado do lar e o mundo com o fito de fazer com que seja possível a transição, de alguma forma, da família para o mundo" (ARENDT, 2003, p. 238). Anteriormente acostumada apenas com o domínio privado, é importante que a criança entre em relação com o espaço humano aos poucos, obviamente de acordo com o seu estágio de desenvolvimento natural, com suas capacidades cognitivas e com suas características singulares.

Mediando esse contato novo encontramos a posição do educador, como representante deste mundo em contínua mudança e pelo qual se deve assumir a responsabilidade. Destarte, a sua autoridade revela-se não apenas na qualificação ou na especialização do mesmo, certamente fatores fundamentais para o sucesso da relação entre o recém-chegado e o mundo, mas principalmente na sua posição de se revelar responsável pela manutenção do domínio humano e para introduzi-lo aos novos.

A qualificação do professor consiste em conhecer o mundo e ser capaz de instruir os outros acerca deste, porém sua autoridade se assenta na responsabilidade que ele assume por este mundo. Face à criança, é como se ele fosse um representante de todos os habitantes adultos, apontando os 
detalhes e dizendo à criança: - Isto é o nosso mundo (ARENDT, 2003, p. 239).

Os educadores também coadunam com essa via dupla de responsabilidade: com o original, trazido pelos recémchegados e com a salvaguarda do mundo. Todavia, esses encargos estão intimamente conectados. As crianças só efetivamente terão à sua disposição a potencialidade revolucionária que desponta a cada novo nascimento se tiverem contato tanto com a herança legada pelos antepassados quanto com a responsabilidade com o futuro, em relação com os que ainda virão (Cf. GORDON, 2001, p. 63). Logo, na perspectiva da teórica, o "ensino para a transformação social requer um esforço constantemente renovado [...]. Como professores [...], vivemos na diferença de tempo entre o passado e o futuro, e somos solicitados [...] a assumir a tarefa de "preservar o novo" em cada geração e em cada criança" (LEVINSON in GORDON, 2001, p. 33).

A importância do educador, mesmo no atípico cenário contemporâneo, ganha visibilidade notória e indiscutível se observarmos a própria teórica que abordamos. A influência de seu professor e orientador, o filósofo Karl Jaspers, abrolha não somente pela sua teoria humana e política, mas pela pessoa que ela veio a tornar-se, enquanto indivíduo e em sua perspectiva acerca do mundo.

Onde quer que Jaspers apareça e fale, tudo se ilumina. Ele tem uma desenvoltura, uma confiança, uma incondicionalidade na fala que nunca vi em nenhuma outra pessoa. Isso me impressionou desde quando eu era muito jovem. Além disso, ele tem uma concepção de liberdade ligada à razão que me era totalmente estranha quando fui para Heidelberg [...]. Vi essa razão em ação [...] e, se posso dizer assim cresci sem pai -, aquilo me educou. Não quero torná-lo responsável por mim, pelo amor de Deus, mas se alguém conseguiu me instilar algum senso das coisas, foi ele (ARENDT, 2011, p. 52).

Para Arendt, portanto, essa via dupla que compõe a educação ganha essencialmente um caráter de conservadorismo. Deve-se ressalvar, todavia, que esse caráter não coaduna com nenhuma escola pedagógica ou mesmo filosófica, porém com a atitude que deve nortear tanto o educador, quanto o sistema educacional inteiro. Assim, nesse contexto, conservadorismo ganha a conotação de conservação, posto que sem o instinto de preservação e permanência do mundo, a educação não apenas não teria sentido, como também sequer seria possível.

Ao mesmo tempo em que necessita desse senso de conservação do espaço em que o homem convive, que funda os corpos políticos e estabelece, portanto, a arte, a educação e a história, o ensino carece da valorização do novo, inerente a cada indivíduo. É o nascimento de novos seres humanos a essência da educação e a possibilidade de renovação constante do mundo. "Exatamente em benefício daquilo que é novo e revolucionário em cada criança é que a educação precisa ser conservadora; ela deve 
preservar essa novidade e introduzi-la como algo novo em um mundo velho" (ARENDT, 2003, p. 243). Com a natalidade, a cada homem que vem ao mundo, surge também um contexto inteiro de novas possibilidades. "A cada nascimento, vem ao mundo algo singularmente novo" (ARENDT, 2009, p. 191).

Essa eterna novidade do mundo, ao passo que torna a educação uma dinâmica constante, também envolve os indivíduos numa responsabilidade conjunta. Afinal, a manutenção do espaço em comum é dever não apenas dos educadores, mas das mais diversas instituições que compõe a teia das relações humanas. Na verdade, ela diz respeito a cada indivíduo, já que todos somos responsáveis pelo espaço de condição de possibilidade da convivência humana. Esse sentimento de cuidado para com o espaço que torna público os homens e as coisas (ARENDT, 2010, p. 47-50) também se desvela como responsabilidade pelo outro e pelas gerações vindouras. Desse modo, por mais que o ensino seja uma atribuição específica, a imputabilidade pelos recém-chegados envolve, de modo geral, as mais diversas esferas que compõe a sociedade humana. Compondo um imperativo humano, em relação à faculdade da natalidade, podemos aferir que:

O que nos diz respeito, e que não podemos portanto delegar à ciência específica da pedagogia, é a relação entre adultos e crianças em geral, ou, para colocá-lo em termos ainda mais gerais e exatos, nossa atitude face ao fato da natalidade: o fato de todos nós virmos ao mundo ao nascermos e de ser o mundo constantemente renovado mediante o nascimento. A educação é o ponto em que decidimos se amamos o mundo o bastante para assumirmos a responsabilidade por le e, com tal gesto, salvá-lo da ruína que seria inevitável não fosse a renovação e a vinda dos novos e dos jovens. A educação é, também, onde decidimos se amamos nossas crianças o bastante para não expulsálas de nosso mundo e abandonálas a seus próprios recursos, e tampouco arrancar de suas mãos a oportunidade de empreender alguma coisa nova e imprevista para nós, preparando-as em vez disso com antecedência para a tarefa de renovar um mundo comum (ARENDT, 2003, p. 247).

A problemática da educação é um imperativo hodierno extremamente relacionado com as questões políticas e com a própria condição humana e, portanto, diz respeito a todos os indivíduos. Arrazoar acerca dessa questão pressupõe além de um esforço de compreensão, um olhar pela própria teoria da autora que abordamos. Considerando que o pensamento, na perspectiva arendtiana, é uma questão eminentemente política e uma saída plausível para o colapso moral contemporâneo, no qual o sistema educacional está imerso, é partindo dessa faculdade que proporemos orientar nossos recursos de pesquisa, afim de identificarmos um eco para a problemática do sistema educacional.

\section{O Pensamento enquanto saída para o colapso contemporâneo}


Arendt percebe a importância de escrever sobre a faculdade humana do pensar a partir do julgamento de Adolf Eichmann, ponto de origem também para seu livro Eichmann em Jerusalém. Tomando por base não apenas o exame jurídico, como também os crimes cometidos pelo burocrata durante o regime instalado na Alemanha entre 1933 e 1945, a análise arendtiana alterou as considerações acerca do problema prático e filosófico do mal. Portanto, se os atos do nazista estavam ligados à irreflexão, e não apenas à um impulso por fazer o mal, mefistofelicamente, ou ainda motivado por puro caráter transcendental, isso significa que tal fenômeno pode estar correlacionado com a atividade do pensamento (ARENDT, 2007). Relativamente à essa conexão entre o mal e o governo do pensar, a autora nos profere que: "foi essa ausência de pensamento [...] que despertou meu interesse [...]. Será possível que o problema do bem e do mal, nossa faculdade para distinguir o que é certo do que é errado, esteja conectado com o pensar?" (ARENDT, 1992, p. 6).

Se o pensamento não se reduz à esfera subjetiva, mas desvela sua importância na prática dos assuntos humanos, na convivência entre eles e no modo como eles aparecem no mundo, a significância deste é iminentemente ativa e política. É inegável a tendência contemporânea da recusa ou ainda da incapacidade de pensar, o que, de modo geral, não significa falta de inteligência ou problemas de cognição. Na perspectiva de Arendt, o pensamento é uma prerrogativa de todos os homens, sendo, portanto, tanto um imperativo universal quanto uma faculdade humana que pode ser exercitada, através do diálogo permanente inerente à essa própria atividade.

A teórica buscou na filosofia platônica a sua definição do pensamento como sendo o diálogo silencioso da alma com ela mesma (PLATÃO, 2001, p. 108). Desse modo, ela define, em primeira instância, o pensar como "diálogo sem som de mim comigo mesmo" (ARENDT, 1992, p. 59). Sendo, portanto, de natureza dialogal, pressupõe-se que existam ao menos dois interlocutores como condição de possibilidade para que essa faculdade efetivamente se dê. Esse exercício de mim com minha consciência, me e self (ARENDT, 1992), possibilita que o pensamento possa se tornar crítico e dialético, posto que a prática dinâmica inerente ao ego pensante, cada vez mais exercitada, torna mais refinado o pensamento.

Se a pluralidade humana se deve ao fato de nossa inerente multiplicidade, o que, como visto anteriormente, deve ser um dos pilares da educação, a dualidade da razão especulativa nos permite vislumbrar essa característica dos homens no plural. Assim, "esse diálogo dos dois-em-um não perde o contato com o mundo dos meus semelhantes, pois que eles são representados no meu eu, com o qual estabeleço o diálogo do pensamento" (ARENDT, 2004, p. 529). Assim, por mais que eu esteja privado da companhia dos demais, a eles me ligo pelo diálogo que estabeleço internamente; a pluralidade que me une aos demais revelase como dualidade interior, possibilitante desta mesma faculdade. "Não sou apenas um. Uma diferença se instala na minha Unicidade” (ARENDT, 1992, p. 137).

Um dos atributos da praticidade do pensar e sua ligação com a educação é que 
ele sempre deriva da experiência. Por mais que essa faculdade exija literalmente que se pare e pense, isto sempre será a partir de algo que passou pelos sentidos, mesmo que não necessariamente esteja agora sendo também por eles apreendido. Isso, obviamente, parece estar na contramão da imediaticidade do mundo, posto que hoje nos é exigido cada vez mais soluções instantâneas, o que torna também a educação voltada para que os recém-chegados sejam preparados para essa velocidade intensa. Porém, educar levando o ego pensante em consideração, valoriza que os discentes exercitem esse diálogo, que pressupõe, por deliberação natural, uma retirada momentânea do mundo das aparências, sensivelmente dado, para discorrer internamente sobre as experiências vividas ou captadas pelos sentidos (ASSY, 2015, p. 58). Assim, todo pensar é também um re-pensar (ARENDT, 1992), ferramenta decisiva para o ensino. "A retirada deliberada do mundo das aparências, do mundo do senso comum, é a condição subjetiva para pensar. Mas a retirada do mundo [...] é acompanhada por um retorno em direção a si mesmo" (SOUKI, 2006, p. 114).

Comunicar o que se foi pensado também faz parte desse processo interno e pode nortear a educação. Assim, não é somente condição sine qua non pensar, mas a possibilidade de exprimir aos outros o que a razão especulativa propõe dialogicamente dinamiza a relação entre os alunos e também com o educador, abrindo espaço para o debate e a construção conjunta de aprendizado. Vazia seria essa faculdade mental se não pudesse relacionar o sujeito com os demais, e não somente com a consciência, podendo tornar pública a unicidade da experiência e a relação singular com o mundo. A conexão direta entre pensamento e linguagem, posto que não há como pensar de modo não-discursivo, é um dos possibilitantes da existência da educação, no sentido próprio de transmissão de conhecimento de caráter científico ou na investigação filosófica pelo significado último das coisas.

A multiplicidade do pensamento implica que aja um encadeamento natural das ideias. Neste diálogo interior, para que os participantes tenham direito à fala, é fundamental que estas não sejam justapostas, mas apresentadas numa sucessão encadeada de argumentação lógica. Tal processo, para Arendt, seria a sequência de pensamento. Caso não houvesse tal encadeamento, pensar seria algo como flashes sem começo, meio e fim, que tornariam o debate crítico impossível. Destarte, por mais que as experiências ou até mesmo os conteúdos de aprendizagem não nos sejam dados ou transmitidos com o mínimo de linearidade e de encadeamento lógico, precisamos transformar esse aparente caos de informações em uma série de conversações do ego pensante.

Todo pensamento é discursivo e, à medida que acompanha uma série de pensamento, poderia ser descrito, por analogia, como "uma linha avançando em direção do infinito", o que corresponde ao modo como usualmente representamos para nos mesmos a natureza sequencial do tempo. Mas, para criar uma tal linha de pensamento, precisamos transformar a justaposição na 
qual as experiências nos são dadas em uma sucessão de palavras proferidas sem som - o único meio que podemos usar para pensar (ARENDT, 1992, p. 152).

O continuum, a mudança permanente na qual o homem está incluído torna o passado o único espectro temporal que possa ser realmente conhecido. Desse modo, enquanto o singular momento no qual o sujeito está inserido é o presente, ele já é findo no momento em que se pensa sobre ele. Para Arendt, o indivíduo vive eternamente na lacuna entre o passado e o futuro e, nesse escorregadio do tempo, apenas uma atividade mental parece ter a capacidade de prolongar internamente o instante temporal do agora: o pensamento. O eterno devir que dinamiza homens e coisas e que possibilita que sejamos impelidos à perplexidade com o mundo, passo inicial para a busca do conhecimento desde o início das ciências e da filosofia, apenas consegue o mínimo de durabilidade através do prolongamento causado pelo ego pensante. É impossível pensar por meio do passado ou do futuro. É no apêndice do presente, na teoria arendtiana denominado nunc stans, que tal faculdade consegue romper com a linearidade temporal, estabelecendo uma espécie de presente imóvel e mais duradouro, condição essencial para a existência do pensamento. É fazendo referência à essa possibilidade humana que podemos falar literalmente em parar para pensar, condição indelével da educação que realmente se proponha a sêlo.

A enérgica atividade do pensamento, sendo ela mesma prática e ensino, posto que é dialógica, e não meramente abstrativa e subjetiva, desvela-se também enquanto ação. Esta é pré-requisito cardinal para a apreensão do mundo e dos fenômenos, posto que, tomando como base a comunicação do dois-em-um, implica em "uma percepção ativa capaz de apreender aquilo que é insuficiente à mera percepção passiva dos sentidos" (ASSY, 2015, p. 6o).

Desse modo, a partir da problemática que envolve a educação, conforme dissertado anteriormente, a faculdade do ego pensante manifesta-se como elemento indispensável de uma análise acerca desta questão. Entretanto, se o pensamento é um dado inquestionavelmente correlato ao ensino, ao esquadrinhar o caráter prático desta dita razão especulativa nos deparamos invariavelmente com a figura de Sócrates. Avistemos o que esse filósofo tem a nos majorar tanto a respeito dessa atividade do espírito humano quanto de sua correlação com a educação.

\section{A Figura de Sócrates}

Partindo do mote inicial: "o que nos faz pensar?" e da assertiva acerca da participação prática e direta do ego pensante nos assuntos humanos, Arendt busca, na análise da história do pensamento, um sujeito que se encontre no limiar escorregadio entre pensamento e ação, ou ainda "um pensador que tenha permanecido sempre um homem entre homens, que nunca tenha evitado a praça pública, que tenha sido um cidadão entre cidadãos, que não tenha feito nem reivindicado nada além do que [...] qualquer cidadão poderia reivindicar" (ARENDT, 1992, p. 126). Obviamente, se estamos defendendo a tese de que o pensar é também 
uma faculdade mental que interfere diretamente na coisa pública e que, por não se reduzir à esfera meramente contemplativa, também tem muito a dizer para a ciência da educação, não seria lógico embasarmo-nos em um pensador que tivesse ficado longe de seus iguais e das implicações objetivas que seu contexto lhe trouxesse.

Para a teórica abordada, Sócrates certamente é a figura que se encaixa de modo ideal neste modelo proposto. Retirando a filosofia da investigação acerca da substância primeira, que seria a essência e a fundação de todas as coisas, e voltando-se para o homem, seus atributos e suas relações, Sócrates acreditava numa busca permanente pelo saber de forma construída. A partir do diálogo, ele confrontaria seus interlocutores sobre conhecimentos que anteriormente poderiam parecer tão claros que questioná-los resultaria em ingenuidade. Porém, a cada indagação socrática, o que restava era nada mais do que os escombros de saberes meramente no nível de senso comum, facilmente demolíveis se confrontados com o método de inquirição do filósofo. "Diálogo e investigação são os princípios pedagógicos e metodológicos usados por Sócrates para fazer filosofia" (SOFISTE, 2007, p. 87).

Não estavam em seu foco investigativo apenas objetos concretos. Ao contrário, ele também perscrutava conceitos abstratos, tais como a justiça, a virtude, e outras características humanas. Suas especulações só tinham sentido se pudessem ser revertidas em conhecimentos práticos e, principalmente, para tornar os homens mais aperfeiçoados, posto que somente assim eles também seriam cidadãos melhores para a polis.

Diz-se que Sócrates acreditava
que a virtude pudesse ser ensi-
nada. E parece que ele realmente
achava que falar e pensar sobre a
piedade, a justiça, a coragem e
coisas do gênero poderiam tor-
nar os homens mais pios, justos e
corajosos, embora nem definição
nem 'valores' lhes fossem dados
para que pudessem orientar sua
conduta futura (ARENDT, 1992,
p. 130).

Para Arendt, Sócrates foi o primeiro filósofo a descobrir o caráter prático do pensamento. "Sustenta que o aparecimento da atividade de pensar e investigar em Atenas representa em si mesma o maior bem algum dia concedido à cidade" (ARENDT, 1992, p. 131). Se homem nenhum é realmente sábio, daí derivam algumas assertivas fundamentais: o conhecimento que se tinha era, na realidade, a nível de senso comum e que "na prática, pensar significa que temos que tomar novas decisões cada vez que somos confrontados com alguma dificuldade" (ARENDT, 1992, p. 133). Nessa conjuntura, algumas definições que Sócrates dava a si mesmo nos auxiliam a alcançar a ligação do ego pensante com a administração ideal da polis e com os únicos modos, de acordo com a figura socrática, que o pensamento pode ser ensinado.

Na Apologia de Sócrates, o próprio pensador se define como um moscardo, que desperta os cidadãos do sono letárgico do senso comum para a atividade do ego pen- 
sante, condição inclusive para que a vida valha a pena ser vivida.

Embora pareça ridículo dizê-lo, que esteja ligado aos deuses e a esta cidade como um forte e generoso cavalo, porém vagaroso por seu tamanho e que requer ser picado por um moscardo para se mexer. Assim a divindade me parece ter unido, sendo o tipo de pessoa que sou à cidade e que devo atiçar-vos e persuadir o povo a reprovar cada um de vós, assediando sem parar o dia todo (PLATÃO, 2013, p. 44).

No Sofista e no Teeteto, Sócrates é a parteira, que ajuda aos demais a livrar-se de suas opiniões e preconceitos infundados, que impedem o ego pensante de se desenvolver internamente e de vir à luz, ganhando dimensão lógica e, trazendo à luz os pensamentos verdadeiros e os relances de um conhecimento que se aproxime da verdade das coisas. "O elemento purificador do pensamento, a maiêutica socrática, que traz à luz as implicações das opiniões não examinadas e com isso as destrói [...] é político por implicação" (ARENDT, 2010, p. 256). Desse modo, para o mal da ignorância há a educação e o método maiêutico é a purificação ideal do pensamento e do discurso contra as contradições, bem como um médico purga e livra seus pacientes dos males que acometem o corpo. "A propósito da alma [...] ela não alcançará do que se lhe possa ingerir de ciência, benefício algum, até que se tenha submetido à refutação, causando-lhe vergonha de si mesma, se tenha embaraçado das opiniões que lhe cerram as vias do ensino" (PLATÃO, 1972, 23od).

No Menon, Sócrates, tal qual a arraia elétrica, que paralisa a todos que a tocam, também entorpece aqueles com quem empreende o diálogo. Sem pretensões de formular nenhum conhecimento impenetrável e definitivo, seu intuito é despertar os demais para o espanto diante do mundo, dos homens e dos fenômenos. "A arraia-elétrica paralisa os outros apenas por estar ela mesma paralisada...Não é que eu deixe os outros perplexos, já conhecendo as respostas. A verdade é que eu lhes transmito minha própria perplexidade" (PLATÃO, 1999, 8oc). Fundamental aqui é perceber que, para a figura socrática, o outro que o interroga e com quem ele divide a sua perplexidade é condição sine qua non para a construção do saber.

No Górgias, Sócrates faz referência direta ao caráter moral do pensamento. É mister que os parceiros do diálogo do doisem-um não estejam em desacordo entre si, e nem tampouco sejam inimigos. "O ensino de Sócrates tinha este significado: só aquele que sabe como viver consigo mesmo está apto para viver com os demais. O 'si mesmo' é a única pessoa da qual não posso me separar [...] e da qual estou unido sem remissão" (ARENDT, 2015, p. 58). Essa discrepância interna impede a faculdade do ego pensante de desenvolver em toda a sua potencialidade. "Seria melhor servir-me de uma lira dissonante e mal afinada, dirigir um coro mal ensaiado, ou estar em desacordo ou em oposição com toda a gente, do que estar comigo mesmo, sendo um, e de me contradizer" (PLATÃO, 2016, 482bc). 
Arendt, como aferimos anteriormente, corrobora que o pensamento tem conotação prática e que suas investigações acerca desta faculdade mental se deram a partir do julgamento de Adolf Eichmann. Desse modo, se o pensamento tem encargo político, a sua ausência é uma ameaça direta a manutenção dos meios de convivência humana. O não-pensar "ensina a aderir rapidamente a tudo o que as regras de conduta possam prescrever em uma determinada época para uma determinada sociedade" (ARENDT, 1992, p. 133). Esse sentido fala diretamente à educação. Se o ensino for percebido apenas como transmissão de conhecimento científico, dependendo da faixa etária e do grau de desenvolvimento do aparato cognitivo, os recém-chegados não se preparam para refinar o diálogo interno do pensamento, aguçando sua criticidade com o interminável jogo de perguntas e respostas entre me e myself, mas apenas tornam-se reprodutores irreflexivos deste conhecimento ou do status quo vigente, títeres do arcabouço político.

Voltando a Sócrates, os atenienses lhe disseram que o pensamento era subversivo, que o vento do pensamento era um furacão a varrer do mapa os sinais estabelecidos pelos quais os homens se orientavam, trazendo desordem às cidades e confundindo os cidadãos [...]. O pensamento apenas desperta, e isto lhe parece um grande bem para a cidade [...]. O significado do que Sócrates fazia repousava nesta simples atividade [...]; o pensamento tem sempre que começar de novo; é uma atividade que acompanha a vida e tem a ver com os conceitos como justiça, felicidade e virtude (ARENDT, 1992, p. 134).

Se a ausência da atividade do pensar traz em si uma ligação com o mal, ou com a degeneração das instituições humanas, é em seus atributos que se encontra uma condição de possibilidade de superar essa questão. Dito de outro modo, se o não-pensar traz em si as origens da questão do mal e da corrupção dos indivíduos, é embasando-nos no ego pensante que encontramos os meios para sobrepujar essa situação-limítrofe, inclusive para a educação.

Sendo o pensamento o diálogo silencioso de mim comigo mesmo, assim como em qualquer relação harmoniosa, é um imperativo que os parceiros do colóquio estejam em equilíbrio. Isso, todavia, não significa que eles estejam em conformidade de pontos de vista acerca dos temas com os quais debatem. Ao contrário, a multiplicidade de juízos favorece o bom-senso e o justo meio fundamentais a um ego pensante contrabalançado. Porém, é fundamental não estar em contradição consigo mesmo nesse dois-em-um, pois estar em desarmonia nesse vínculo perpétuo é tornar-se inimigo de si mesmo, ou de sua consciência. Ser hostil a si mesmo é tornar-se seu próprio adversário, a única companhia que testemunha o indivíduo e o interroga ininterruptamente.

Para Sócrates, a dualidade do dois-em-um significava apenas que quem quer pensar precisa tomar cuidado para que os parceiros do diálogo estejam em 
bons termos, para que eles sejam amigos. $\mathrm{O}$ parceiro que desperta novamente quando estamos alertas e sós é o único do qual nunca podemos nos livrar - exceto parando de pensar (ARENDT, 1992, p. 141).

A não-contradição entre os parceiros deste diálogo é um ponto fundamental em comum de pessoas com senso moral mais apurado. Pessoas com deficiência em sua consciência moral, em discordância consigo mesmas, evitam a companhia de si próprias, desta testemunha que nunca as abandona. "Nenhum homem pode manter sua consciência intacta se não pode atualizar este diálogo consigo mesmo" (ARENDT, 2015, p. 62). Assim, o exame diante de atos e do próprio conhecimento só é possível a partir do pensamento. "Uma pessoa que não conhece essa interação silenciosa (na qual examinamos o que dizemos e fazemos) não se importa em contradizer-se, e isso significa que ela jamais quererá ou poderá prestar contas do que faz ou diz" (ARENDT, 1992, p. 143).

Porém, a ausência dessa interação interna não é um problema de aprendizado, ou ainda estupidez, mas a carência da prática desse diálogo, o que pode ocorrer a qualquer indivíduo, posto que o pensamento é um pressuposto de todos, e não de alguns poucos. Se esquivar dessa faculdade é totalmente possível, porém, as consequências de não pôr em exame nem os atos individuais e nem o contexto em que se vive é uma armadilha perigosa, que a contemporaneidade tornou palpável sob o signo do totalitarismo.
$\mathrm{O}$ pensamento, em seu sentido não-cognitivo e nãoespecializado, como uma necessidade natural da vida humana [...] não é uma prerrogativa de poucos, mas uma faculdade sempre presente em todo mundo; do mesmo modo, a inabilidade de pensar é [...] uma possibilidade sempre presente para todos [...]. Todos podemos vir a nos esquivar daquela interação conosco mesmos, cuja possibilidade concreta e cuja importância Sócrates foi o primeiro a descobrir [...]. Uma vida sem pensamento é totalmente possível, mas ela fracassa em desabrochar a sua própria essência - ela não é apenas sem sentido; ela não é totalmente viva. Homens que não pensam são como sonâmbulos (ARENDT, 1992, p. 143).

O pensamento não é o mesmo que o conhecimento, apesar de ser a sua pedra angular. Numa sociedade extremamente tecnológica e de informações velozes, o poder de solapar as supostas verdades estabelecidas vai na contramão do que é mister para o establishment vigente. $\mathrm{O}$ ego pensante, saindo da marginalidade dos assuntos humanos, da dimensão contemplativa, e se mostra uma saída essencialmente prática em situações-limite e em emergências políticas. "O hábito de examinar tudo o que se apresenta por si-mesmo é então a condição necessária e suficiente para nos proteger de muitas catástrofes" (VALÉE, 1999, p. 40). Nessas conjunturas, pensar configura-se como um modo de ação.

Nesses momentos, em que a educação, em especial, se volta apenas à cientifi- 
cidade dos saberes e das disciplinas e esquece de promover o despertar dos recémchegados para a reflexão sobre a realidade dada em primeira instância, a figura socrática se mostra como um modelo de método para fundamentar o diálogo do pensamento, de modo que ele se torne o mais crítico e humanizado possível, sem esquecer a importância do outro na construção da perspectiva acerca do que é o mundo, o homem, e os fenômenos aos quais os diversos níveis da educação tentam abarcar e despertar. Trazer o método socrático, nesse contexto, exige a superação da simples cópia ou reprodução. Ser recém-chegado e discente, portanto, é também ser protagonista ou cocriador dessa relação de aprendizado. O apoio do educador ao cultivo e ao desenvolvimento do pensar investigativo e intersubjetivo, ou entre-homens é mister em um ensino que se baseie, tal como Sócrates já o fazia, na busca por retirar das pessoas a verdade que há em potência em cada uma, dando à luz a um conhecimento e entendimento para além do meramente apreendido pelos sentidos (ARENDT, 2015). "Na Investigação Dialógica, o educando conceitua, interpreta, raciocina, investiga, relaciona com o outro [...] e o educador [...] torna-se um parceiro de investigação, convivência e diálogo na criação de conhecimentos e valores” (SOFISTE, 2007, p. 88).

Destarte, a educação que se baseie na Investigação Dialógica se articularia entre duas competências principais. Num primeiro eixo o foco seria a aquisição do conhecimento, o aperfeiçoamento das capacidades de raciocínio lógico e de inferência, bem como a valorização da reflexão, da curiosidade e da iniciativa. Tais habilidades se re- lacionam diretamente com o cultivo da postura científica e a formação da necessidade de investigar para o ensino. $\mathrm{O}$ outro eixo destina-se à habilitar o aluno-sujeito à convivência, a autonomia, ao trabalho em equipe, à consideração do outro na percepção da realidade e o diálogo crítico. Nota-se que, em ambos os eixos, a disposição ao pensar, enquanto relação, é posta em destaque (SOFISTE, 2007). Além disso, despertar para a convivência e para a percepção do mundo a partir do ponto de vista do outro, além de ser um baldrame do ensino que considere a Investigação Dialógica, é a fundação do pensamento político por excelência (ARENDT, 2015).

A urgência de repensarmos a educação tomando como base as necessidades impostas pelas questões tipicamente contemporâneas pressupõe uma análise acerca da ciência pedagógica e, fundamentalmente, acerca da responsabilidade que temos diante dos novos e do mundo. $\mathrm{O}$ método dialético de investigação analítica, empreendido pela figura socrática, certamente representam uma saída eficaz, voltada para uma ética humanizadora e para uma educação de excelência (SOFISTE, 2007). Despertar os novos para a importância do exame constante proposto pela razão especulativa desvela-se taxativamente uma necessidade de nossa educação, tanto quanto o repasse coerente de conteúdos disciplinares. "A manifestação do vento do pensamento não é o conhecimento; é a capacidade de distinguir o certo do errado, o belo do feio. E isso, na verdade, pode impedir catástrofes, pelo menos para mim, nos raros momentos em que as cartas estão abertas sobre a mesa" (ARENDT, 2010, p. 257). 
Se é comunicando nossos pensamentos através da linguagem que é possível transmitir conhecimentos e perspectivas acerca do mundo, é verossímil também aferir que é a disposição de viver bem conosco mesmo, já que somos duais, que nos incita para a importância política do pensar. É ele que ajudará o sujeito a decidir quem terá como companhia, bem como ele aparecerá aos demais. O diálogo sem som do indivíduo consigo mesmo, levado ao plano da esfera pública, conduz à consideração da opinião do outro e, consequentemente, a capacidade de se colocar no lugar dele. Nesse sentido, a faculdade do ego pensante não somente é a quintessência da vida humana, como também é uma das formas eficazes de reconstrução da dignidade humana, como também da valorização das instituições, como as ciências da educação, e do resgate da coisa pública.

\section{A Permanente renovação do mundo comum}

Percebendo a oportunidade de exame e de renovação por trás da crise política que se desvela também sobre a educação, Arendt analisa o ensino relacionando as questões caracteristicamente contemporâneas que o envolvem com o próprio propósito e a essência deste. $\mathrm{O}$ imperativo que fundamenta as ciências da educação é basicamente o movimento constante inerente à natalidade. Os recém-chegados nascem e precisam ser introduzidos no mundo, não apenas através do cientificismo das disciplinas ou do desenvolvimento das habilidades específicas, objetos certamente notáveis, mas indispensavelmente através do contato com o que seja a realidade dos estabelecimentos humanos e a responsabilidade com o espaço preexistente no qual eles abeiraram-se. Para tal intento, os educadores devem voltar-se primordialmente tanto para o contato com a tradição, com o que fundamenta a realidade tal como ela se constitui, quanto para a valorização do novo e da possibilidade da fundação de algo inesperado, inerente a cada indivíduo.

Porém, o período hodierno lançou sob a educação questões urgentes e que prescindem de respostas igualmente cogentes. "Que tipo de educação é particularmente apropriada para preparar as pessoas para entender política? Como alguém pode ser educado para aprender? Qual a relação entre educação e política?" (YOUNG-BRUEHL in GORDON, 2001, p. 225). Para se posicionar diante de tantas questões impostas pelo nosso tempo, o ensino deve olhar para o seu próprio cerne, como também para o indivíduo, princípio e fim desta atividade, para buscar os ecos de enfrentamento das perguntas que se revelam na atual conjuntura. É neste mote que o pensamento e a influência instigante despertada pela figura socrática apresentam-se como meios de enfrentamento frente aos desafios impostos à educação.

Se, de fato, é impossível pensar num modelo de educação que prescinda da faculdade do ego pensante, todavia este ultrapassa o mero raciocínio lógico ou a cognição mais especializada. $\mathrm{O}$ pensamento enquanto diálogo tem como condição de possibilidade a relação entre os interlocutores dessa comunicação. Que eles não estejam em contradição é o requisito principal para que o equilíbrio do pensar se dê, e o 
exercício dessa conversação conflui para o desenvolvimento constante da criticidade. Dessa mesma forma, tomando a razão especulativa como uma faculdade prática inerente a todo ser humano, porém que necessita ser aperfeiçoada, é na figura de Sócrates que a investigação e o diálogo, enquanto métodos científicos e de construção de conhecimento compartilhado, desvela-se como um referencial metodológico de como o pensamento se mostra, em caráter objetivo, na teia das relações humanas e como pode ser aplicado na educação contemporânea.

Visando responder às três questões que apresentamos anteriormente, Arendt escreveu e vivenciou a educação. Toda sua teoria dialoga com a oportunidade do novo, que cada criança traz ao mundo através do seu aparecimento biológico (ARENDT, 2009). Além de ser o baldrame do ensino, essa permanente renovação do mundo comum traz em si toda a esperança e o surpreendente característicos de tudo aquilo que é inesperado. Todavia, para além da instrução e do requinte de habilidades, cabe ao sistema educacional e aos educadores edificar o senso de pertencimento e de edificação com o mundo. Neste instante em que desponta no indivíduo a responsabilidade e o amor com esse espaço de convivência inter-humano, não somente o sujeito nasceu novamente para esse campo de relações, como também a própria educação realizou o imperativo hodierno de tornar as crianças verdadeiramente humanas. Os processos históricos que culminaram com as situações-limite contemporâneas fazem com que humanizar os recém-chegados seja tão importante quanto transmitir-lhes o conhecimento fenomênico da realidade. Se comumente atribui-se a responsabilidade da formação das gerações ao sistema educacional, é estimulando conjuntamente o pensamento, o diálogo e a investigação que logrará êxito a missão educativa de introduzir os novos à necessária e sempre espantosa eterna novidade do mundo.

\section{Referências}

ADORNO, Theodor W. Educação e Emancipação. São Paulo: Editora Paz e Terra, 2012.

ARENDT, Hannah. A condição humana. Trad. Roberto Raposo. 10aㅡ ed. Rio de Janeiro: Editora Forense Universitária, 2009.

ARENDT, Hannah. A Vida do Espírito. Trad. Antônio Abranches e César Augusto de Almeida. Rio de Janeiro: Editora Relume-Dumará, 1992.

ARENDT, Hannah. Compreender. Formação, Exílio e Totalitarismo. Trad. Denise Bottman. São Paulo: Editora Companhia das Letras, 2011.

ARENDT, Hannah. Eichmann em Jerusalém. Um relato sobre a Banalidade do Mal. Tradução de José Rubens Siqueira. São Paulo: Editora Companhia das Letras, 2007. 
ARENDT, Hannah. Entre o Passado e o Futuro. Trad. Mauro W. Barbosa. $5^{\text {a }}$ ed. São Paulo: Editora Perspectiva, 2003.

ARENDT, Hannah. Escritos Judaicos. Trad. Laura Degaspare Monte Mascaro, Luciana Garcia de Oliveira e Thiago Dias da Silva. Barueri: Amarilys, 2016.

ARENDT, Hannah. La promessa de la política. Buenos Aires: Paidós, 2015.

ARENDT, Hannah. Origens do Totalitarismo. Trad. Roberto Raposo. São Paulo: Editora Companhia das Letras, 2004.

ARENDT, Hannah. Responsabilidade e Julgamento. Trad. Rosaura Eichenberg. São Paulo: Editora Companhia das Letras, 2010.

ASSY, Bethania. Ética, Responsabilidade e Juízo em Hannah Arendt. São Paulo: Perspectiva/ Instituto Norberto Bobbio, 2015.

GORDON, Mordechai. Hannah Arendt and Education. Renewing our Common World. Oxford: Westview Press/ Perseus Books Group, 2001.

PLATÃO. Apologia de Sócrates. Trad. Alexandre Romero. São Paulo: Hunter Books, 2013.

PLATÃO. Górgias. Tradução de Edson Bini. São Paulo: Edipro, 2016.

PLATÃO. Menon/Banquete/Fedro. Rio de Janeiro: Ediouro, 1999.

PLATÃO. Sofista. Trad. Jorge Paleikat e João Cruz Costa. São Paulo: Abril Cultural, 1972.

PLATÃO. Teeteto/Crátilo. Trad. Carlos Alberto Nunes. Belém: EDUFPA, 2001.

SOFISTE, Juarez Gomes. Sócrates e o Ensino da Filosofia. São Paulo: Editora Vozes, 2007.

SOUKI, Nádia. Hannah Arendt e a Banalidade do Mal. Belo Horizonte: Editora UFMG, 2006.

VALÉE, Catherine. Hannah Arendt, Sócrates e a Questão do Totalitarismo. Trad. Armando Pereira da Silva. Lisboa: Instituto Piaget, 1999.

Recebido em: $17 / 04 / 2017$

Aprovado em: 31/10/2019 